\title{
Two-way MANCOVA: An application to public health
}

AIP Conf. Proc. 1479, pp. 1716-1719; doi: http://dx.doi.org/10.1063/1.4756503

NUMERICAL ANALYSIS AND APPLIED MATHEMATICS ICNAAM 2012: International Conference of Numerical Analysis and Applied Mathematics

Date: 19-25 September 2012

Location: Kos, Greece

M. R. Ramos ${ }^{1}$, E. Carolino ${ }^{2}$, T. Oliveira ${ }^{3}$, and M. Bicho ${ }^{4}$

${ }^{1}$ Universidade Aberta, Rua da Escola Politécnica, no 141-147, 1269-001 Lisbon, Portugal and CMAF - Center for Mathematics and Fundamental Applications, University of Lisbon, Portugal ${ }^{2}$ EST\&SL - IPL and Genetics Laboratory, FML-University of Lisbon, Portugal

${ }^{3}$ Universidade Aberta, Rua da Escola Politécnica, no 141-147, 1269-001 Lisbon, Portugal and dCEAUL- Center of Statistics and Applications, University of Lisbon, Portugal

${ }^{4}$ Genetics Laboratory, FML-University of Lisbon, Portugal

\section{ABSTRACT}

The aim of this work is to use the MANCOVA model to study the influence of the phenotype of an enzyme - Acid phosphatase - and a genetic factor - Haptoglobin genotype - on two dependent variables - Activity of Acid Phosphatase (ACP1) and the Body Mass Index (BMI). Therefore it's used a general linear model, namely a multivariate analysis of covariance (Twoway MANCOVA). The covariate is the age of the subject. This covariate works as control variable for the independent factors, serving to reduce the error term in the model. The main results showed that only the ACP1 phenotype has a significant effect on the activity of ACP1 and the covariate has a significant effect in both dependent variables. The univariate analysis showed that ACP1 phenotype accounts for about $12.5 \%$ of the variability in the activity of ACP1. In respect to this covariate it can be seen that accounts for about $4.6 \%$ of the variability in the activity of ACP1 and $37.3 \%$ in the BMI.

Keywords: biochemistry, covariance analysis, enzymes, genetics, molecular biophysics

ISSN

0094-243X (print)

1551-7616 (online)

ISBN

$978-0-7354-1091-6$

(C) 2012 American Institute of Physics 